\title{
PERCEPTIONS OF ONLINE VERSUS FACE-TO- FACE LEARNING OF EDUCATIONAL LEADERSHIP GRADUATE STUDENTS
}

\author{
Dr. Paulette Harris \\ Dr. Samuel Hardy, III \\ Dr. Olajide Agunloye, \\ Dr. Doug Hearrington \\ Georgia Regents University
}

\begin{abstract}
A descriptive study was conducted using a researcher-created survey of students $(\mathrm{N}=10)$ enrolled in online M.Ed. courses in Educational Leadership during the fall of 2012. The purpose or this study was to determine student perceptions of learning in an online setting versus a traditional setting. Key findings of the study indicate that because of ease of use, convenience, and flexibility online courses do not detract from learning vis-à-vis courses delivered under a traditional format. For program development, future researchers could continue our exploration of ease of use, convenience, and flexibility in educational leadership courses.
\end{abstract}

Keywords: Traditional face to face instruction, online learning, leadership, educational leadership

\section{Introduction}

Perceptions of Online Versus Face-To-Face Learning of Educational Leadership Graduate Students

In 2012, more than 6.7 millionstudents in the United States were enrolled in at least one online course (Sloan, 2013). Yet, studies continue to demonstrate that university professors question whether or not online learning environments exposestudents to complex learning tasks. They ponder, also, whether such students are intrinsically motivated in online environments and if adequate student interactions take place and represent true performance-based learning experiences (Kester, Kirschner, \&Cobalan, 2006).

Researchers continue to wonder if today's online environments provide enough carefully guided interactive student postings, threaded 
discussions and other selected onlineinteractive modalities (Woo \& Reeves, 2007). Ward, Peters, and Shelley (2010) point out that their findings confirm those of others(e.g., Woo \& Reeves, 2007) who contend that professors must continue to query whether online environments positively impact university student learning. In fact, Ward et al. (2010) found the success of the online learning environment is mixed.

Chen and Shaw (2006) examined meaningfulness of theinteractive processes in face-to-face, hybrid and online environments. Over time, they reported no differences between the instruction given face-to-face versus online.Ritter, et al. (2010) examined the perceptions of graduate students enrolled in educational leadership programs that were either face-to-face, online, or hybrid. Using an emailed survey to measure participant's sense of community, connectedness, and learning, students were asked to respond to twenty items using a five point Likert scale, ranging from strongly disagree to strongly agree (Ritter et al. 2010). They used the Classroom Community Scales by Rovai (2002) to collect data from126 participants.Findings indicated that university graduate students noted having developed a greater sense of community in face-to-face environments and hybrid environments over strictly online situations. However, there was no statistical difference in the perceptions of learning in either the face-to-face, online, or hybrid courses.

Sherman, Crum and Beaty (2010) explored many aspects of student's perceptions of their online course in educational leadership. By sending out a survey link to students in the educational leadership department at two universities, students' experiences with the online courses and perceptions of their effectiveness were rated using a five-point Likert scale, also ranging from strongly disagree to strongly agree. The responding students reflected positively on their experience in their online courses and indicated plans to take future online courses. In addition, the majority of students felt that their online courses allowed them to make connections between theory and practice, demonstrate their knowledge and practice, and prepare them to serve as leaders. However, they also indicated that they would prefer hybrid courses that combined online and face-to-face interactions versus just online courses or face-to-face classes. Overall, the research of Sherman, Crum, and Beaty (2010) noted that after more than a decade of research examiningonline versus face-to-face-versus hybrid learning environments (particularly in regards to successful learning platforms for graduate students in educational leadership), many questions are still unanswered. This study examines the perceptions of students on the comparative effectiveness of online and face-to-face learning environments in meeting specified learning goals in a university setting and will take steps toward answeringone of those unanswered questions. 


\section{Method}

Participants in this study $(\mathrm{N}=10)$ were students in an online Master's degree program in Educational Leadership.The purpose of the study was to determine student perceptions of the effectiveness of online courses versus traditional courses.

The methodological approach for this study was survey research of a convenience sample of students $(\mathrm{N}=10)$ following Mertler and Charles' (2011) approach to describing the characteristics of a sample at a given point in time (p.233). Thisapproach was appropriate because the researchers were interested in only the perceptions of the respondents during one semester of study toward either online courses orf2f courses.

The study was designed to answer the following three main research questions:

1. Which mode of course delivery, online or traditional, do students perceive better helps them to meet their specified learning outcome goals?

2. Which instructional method, online or traditional, do students perceive presents more challenges in meeting their specified learning outcome goals?

3. How can the online learning environment be improved to better support students in meeting their specified learning outcome goals?

\section{The Survey}

The survey instrument was comprised of 13 open-ended items. The questionnaire was developed by the faculty teaching the online courses, and items were reviewed by two research professors. An advised consent agreement was provided in the questionnaire explaining the voluntary nature of the study, and each respondent was provided with the option to withdraw from the survey at any time. .

The questions in the survey fall within four general topic headings: reasons for enrolling in an online class, enabling conditions between online and f2f classes, platformchallenges issues and learning outcomes perceptions. Conclusions from the question responses are reported below.

Data from the surveys were gathered from early November, 2012 through early December, 2012. Questionnaires were sent to 24 students with 10 responding, for a $42 \%$ response rate. Follow-up questions soliciting the reasons for the lack of responses from the remaining students were sent to all the 14 students who did not respond. Again, none of the 14 students responded to the follow-up questions. This research study is not a population-based study; therefore, the results cannot be deemed as generalizable to a population of graduate students taking online courses. Any 
interpretations and conclusions from this study are only applicable to the 10 students who responded. The researchers' conclusions are based upon the assumption that all respondents' answers were truthful.

\section{Method of Analysis}

The responses given for each question in the survey were assessed by the researchers and grouped by themes and issues emerging from the respondents' answers based on the descriptors used in the narrative responses. Most of the questions were answered by all 10 of the respondents; although several questions were answered by only nine of the respondents. For follow-up questions to which students had indicated affirmative responses in previous parent questions 'Not Applicable' responses were grouped as agreement responses.

\section{Results}

The tables below show a summary of the dimensional analysis of the responses; grouped by emerging themes and issues.

Table 1 indicates the percentage of responses aligned to the corresponding response themes indicated.

Table 1: Reasons for Taking Online Classes

\begin{tabular}{|c|c|c|}
\hline Survey Domain & Response Themes & Percentage \\
\hline \multirow{4}{*}{ Reasons } & Convenience & $70 \%$ \\
\cline { 2 - 3 } & More reflection on learning & $10 \%$ \\
\cline { 2 - 3 } & Required class and availability & $10 \%$ \\
\cline { 2 - 3 } & Preferred Professor & $10 \%$ \\
\hline $\begin{array}{c}\text { Degree to Which Reasons } \\
\text { Were Satisfied }\end{array}$ & All Reasons Were Satisfied & $100 \%$ \\
\hline
\end{tabular}

A majority (70\%) of respondents indicated 'Convenience' as the reason for taking online class. 'More Reflection on Learning'; 'Required Class and Availability'; and 'Preferred Professor were each $10 \%$.

The responses on enabling conditions for online course are summarized in Table 2.

Table 2: On-line Course Enabling Conditions

\begin{tabular}{|c|c|c|}
\hline Survey Domain & Response Themes & Percentage \\
\hline \multirow{3}{*}{ Enabling Conditions } & Convenience & $30 \%$ \\
\cline { 2 - 3 } & Flexibility & $30 \%$ \\
\cline { 2 - 3 } & Eelf-directedness and Time Management & $30 \%$ \\
\cline { 2 - 3 } & Engaging Discussion Session & $10 \%$ \\
\hline
\end{tabular}

'Convenience', 'Flexibility', and 'Engaging Discussion Sessions' were the reasons cited by $90 \%$ of respondents. Ten percent cited 'Selfdirectedness and Time Management' as the enabling condition for taking an online course. 
Table 3 depicts the perceived enablers in f2fclasses when compared with online classes.

Table 3: Perceived Enablers in Face-to-Face Classes Compared to Online Classes

\begin{tabular}{|c|c|c|}
\hline Survey Domain & Response Themes & Percentage \\
\hline \multirow{4}{*}{$\begin{array}{c}\text { Perceived Face-to-face } \\
\text { Enabling Conditions }\end{array}$} & No perceived difference & $40 \%$ \\
\cline { 2 - 3 } & $\begin{array}{c}\text { More opportunity for 'Teachable } \\
\text { Moments' }\end{array}$ & $20 \%$ \\
\cline { 2 - 3 } & $\begin{array}{c}\text { More opportunity for face-to-face } \\
\text { interactive participation }\end{array}$ & $30 \%$ \\
\cline { 2 - 3 } & Required attendance and presence & $10 \%$ \\
\hline
\end{tabular}

Forty percent of respondents perceived no difference between faceto-face and online methods of delivery. Thirty percent felt that face-to-face provides more opportunity for direct physical interaction between learners, while $20 \%$ responded that face-to-face provides more opportunity for 'teachable moments'. A summary of the challenges faced by learners in the online learning environment is shown in Table 4.

Table 4: Challenges in the Online Learning Environment

\begin{tabular}{|c|c|c|}
\hline Survey Domain & Response Themes & Percentage \\
\hline Challenges in Online & None & $70 \%$ \\
\cline { 2 - 3 } Environment & Navigational Challenges & $30 \%$ \\
\hline Challenges overcame & All challenges were overcame & $100 \%$ \\
\hline
\end{tabular}

Seventy percent of the respondents indicated that they did not face any challenges. Only $30 \%$ indicated they faced Navigational Challenges. The relative advantage of online vs. f2f in enhancing leadership knowledge and skills are summarized in Table 5.

Table 5: Online Delivery vs. Face-to-Face in Enhancing Leadership Knowledge and Skills

\begin{tabular}{|c|c|c|}
\hline Survey Domain & Response Themes & Percentage \\
\hline \multirow{3}{*}{ Knowledge and Skills } & $\begin{array}{c}\text { More Self-directedness and time } \\
\text { management skills }\end{array}$ & $50 \%$ \\
\cline { 2 - 3 } & $\begin{array}{c}\text { More focused on closer analysis of } \\
\text { content topics }\end{array}$ & $20 \%$ \\
\cline { 2 - 3 } & No difference & $30 \%$ \\
\hline
\end{tabular}

On questions relating to the relative advantage of online delivery vs. f2f in enhancing leadership knowledge and skills, $50 \%$ of respondents indicated that online delivery is more advantageous in promoting selfdirectedness and time management. Twenty percent indicated that online delivery improved their abilities to be more focused and with closer analysis of content topics compared to f2f. Thirty percent indicated that there is no difference between the two delivery platforms in terms of relative advantage in leadership knowledge and skills acquisition. 
Table 6 is a summary of the responses to the questions relating to what would have been different had the mode of delivery been a face-to-face instead of online.

Table 6: What Would Have Been Different if Delivery Was Face-to-Face

\begin{tabular}{|c|c|c|}
\hline Survey Domain & Response Themes & Percentage \\
\hline \multirow{3}{*}{$\begin{array}{c}\text { What Would Have Been } \\
\text { Different }\end{array}$} & Not as Self-directed & $30 \%$ \\
\cline { 2 - 3 } & More interaction with professor & $20 \%$ \\
\cline { 2 - 3 } & Less time dedicated to learning activities & $10 \%$ \\
\cline { 2 - 3 } & No difference & $40 \%$ \\
\hline
\end{tabular}

On the question regarding what would have been different if the mode of delivery was f2 $\mathrm{f}$ instead of online, 30\% responded that they would not have been more self-directed in a face-to-face setting compared to online. Twenty percent indicated that online provided more opportunity for learning while $40 \%$ responded that there would have been no difference.

\section{Discussions and Conclusions}

The following patterns have emerged from the results of this study.

- Majority of the respondents (70\%) take online courses because of convenience. Convenience includes considerations such as timemanagement, flexibility, and fitness within other personal obligations.

- Compared to face-to-face, three factors were cited as relative advantages for online learning. The enablers are convenience, flexibility, and engagement in discussion sessions. All of the students in the graduate program were adults. This finding is in line with how adults learn.Adult learning posits that adults learn at a self-directed pace and in environments where they can freely exchange knowledge and learning experiences (Knowles, 1980). The online environment seemed to provide these opportunities.

- Compared to online, it is worthy of note that $20 \%$ of respondents indicated that face-to-face platforms provide opportunities for occasional 'Teachable Moments.'Teachable Moments occur when a teaching and learning process spontaneously brings out assumed misconceptions and/or begins to extend the learning and knowledge process beyond pre-determined boundaries. Although teachable moments can also occur through discussion sessions in online environments, the online instructor has to be more intuitive and to elicit these moments in online discussion sessions.

- Contrary to common perception, $70 \%$ of respondents stated that they did not face any insurmountable challenges using the online learning platform. This is an important finding that can help to puncture the notion that online learning environments are fraught with challenges, 
especially navigational challenges. Theseissues may have been mitigated because the quality of the course layout and studentfocused considerations which went into planning the online courses during the course development process. All courses in the program were assessed and approved through a third party quality review.

- Self-directedness, time management, and closer analysis of content were the knowledge and skills takeaways from online delivery by a majority of the respondents. This again ties into the way adults learn and process information.

- Also, worthy of note is that only $20 \%$ of respondents felt that face-toface would provide more interaction with the professor than would an online delivery mode and that face-to-face is less self-directed when compared to online delivery platforms (30\%). Forty percent felt that nothing would have been different in either delivery platform. This is an indication that if conditions are equal, graduate students in educational leadership may prefer an online course delivery mode to face-to-face.

In conclusion, the considerations that make online classes preferable to face-to-face classes for graduate students in Educational Leadership include, but are not limited to: ease of use, convenience, flexibility, selfdirectedness, time-management, and engaging discussion sessions. The considerations that make face-to-face preferable include minimal selfdirectedness and opportunity for more direct and physical interaction with the professor.

\section{Limitationsand Expectations for Follow-up Study}

This study was focused on online courses in a specific educational leadership preparation program. Although the results of this study may inform others delivering, designing, or managing online programs, they are not necessarily generalizable to other contexts. There is a need to expand this research to other courses in other programs to improve the generalizability of the findings and the conclusions.

\section{References:}

Allen, E., \& Seaman, J. (2010).Learning on demand: Online education in the United States.

Needham, MA: Scan-C.

Chen, C., \& Shaw, R. (2006). Online synchronous vs. asynchronous software training through the behavioral modeling approach. International Journal of Distance Education Technologies, 4(4), 88-102. 
Ho, C., \& Swan, K. (2007). Evaluating online conversation in an asynchronous learning environment. The Internet and Higher Education, 10(1), 3-14.

Kester, L., Kirschner, P., \&Corbalan, G. (2006). Designing support to facilitate learning in powerful electronic learning environments. Computers in Human Behavior, 23(3), 1047-1054.

Knowles, M. (1980).The modern practice of adult education:From pedagogy to andragogy.

New York: Cambridge.

Mertler, C.A. \& Charles, C.M. (2011).Introduction to educational research.(7 ed.).

Boston: Pearson.

Ritter, C., Polnick, B., Fink, R., \&Oescher, J. (2010). Classroom learning communities in educational leadership: A comparison study of three delivery options. Internet and Higher Education, 13, 96-100.

Rovai, A. (2002). Development of an instrument to measure community.The Internet and Higher Education, 5, 197-211.

Sherman, W., Crum, K., \&Beaty, D. (2010). Perspectives on distance technology in leadership education. Journal of Research in Leadership Education, 5(13), 589-610.

Sloan Consortium (2013). Changing course: Ten years of tracking online education in the united states. The Sloan Consortium, Retrieved from http://sloanconsortium.org/publications/survey/changing_course_2012 Woo, Y., \& Reeves, T. (2007). Meaningful interaction in web-based learning: A social constructivist interpretation. The Internet and Higher Education, 10(1), 15-25. 